\title{
Understanding mobile banking from a theoretical lens: Case studies of selected Kenyan m-banking products
}

\author{
Martina Mutheu Mulwa \\ Lecturer School of Journalism and Mass Communication, University of Nairobi. \\ Main Campus, Education Building, 3rd Floor. P.O. Box 30197-00100 Nairobi, Kenya.
}

Timothy Mwololo Waema

Professor of Information Systems in the School of Computing and Informatics in the University of Nairobi. P.O. Box 15742, 00100, Nairobi, Kenya

\begin{abstract}
Characteristic of every developing nation, Kenya has found itself at crossroads; defining the banking industry with the urge to provide banking services to majority of the unbanked populations. Mobile banking is a banking model that has been adopted by Kenyan Banks to reach out to unbanked populations. This paper is based on a case study conducted in Kenya on selected mobile banking products in 2012. The Actor Network theory methodology was used to identify and follow actors. Using in-depth interviews with key informants, survey of users and agents as well as focus group discussions and observation, it was established that agent phones and Point of service (POS) devises were used to deliver traditional banking services to users whose access mode was their mobile phone or debit cards. There existed partnerships between banks and mobile network operators whose operations were regulated by the Central Bank of Kenya and the Communications Authority of Kenya. This paper seeks to explore fundamental requirements for the interplay of actors in the execution of mobile banking services. It critically analyses data collected, with reference to the Network Society theory by Manuel Castells and Actor Network theory by Michael Callon and Bruno Latour, to inform on cross-sectoral partnerships and user attributes necessary in mobile banking uptake and use.
\end{abstract}

\section{Keywords}

Mobile banking, network formation, Network society, Actor Network Theory, cross-sectoral partnerships

\section{Academic Discipline And Sub-Disciplines}

Information Communication Technology

\section{SUBJECT CLASSIFICATION}

Communication

TYPE (METHOD/APPROACH)

Case Study

\section{Council for Innovative Research}

Peer Review Research Publishing System

Journal: International Journal Of Management \& Information Technology

Vol . 10, No 8

editorsijmit@gmail.com

www.jimit.com 


\section{Introduction}

The banking industry in Kenya has seen a tremendous transformation following the release of regulations (Agency Banking Act, 2010) allowing banks to offer services through third party agents. Kenya Commercial Bank (KCB), Cooperative Bank and Equity Bank, all financial institutions with a large retail distribution chain among others, have rolled out agent banking networks to provide an extension of services to segments that may have been difficult to harness through the traditional bank branch model. By tapping into these markets through the wireless communication technology, mobile banking is emerging as a preferred channel for banking and financial services because of the ubiquitous nature of mobile devices and services, and the ability of mobile banking services to reduce overall operational costs, streamline operations, and expand customer base through flexibility. These services could be both transformational and additive (Porteous (2007).

With glaring possibilities exhibited by models like M-pesa (Martina, Ndati 2013), telecom providers now view financial content as a viable business and also appealing because a combined banking mobile communications product is a way for wireless telecoms to move beyond commodity voice services and differentiate their products to improve customer retention. Another attraction is that financial information is already stored and transmitted in precisely the form that allows it to be delivered by wireless means. In fact, it is the raw material of the existing telecom franchise. Besides, wireless communication delivers the interactivity to perform transactions on the spot.

Recent statistics (CCK operator returns 2014) in Kenya indicate that $89.1 \%$ of Kenyans have access to mobile phones compared to ownership of $79.2 \%$ meaning that people share phones in a household or in the community. Most people are therefore comfortable paying for various commodities using the phone and adding banking to these services, can hardly be a stretch. A natural transition is strategic in the diffusion of products targeting BOP populations (Fredrik, B. and Martin, P. (2009). In addition, successful innovations in retail finance allow people to manage their lives on their own terms (Wouter et al., 2010) and the mobile phone is in that mold. Today, people usually don't leave home without their mobile phones, so using the phone as a cashless way to make payments is certainly as convenient as using other traditional methods they are accustomed to. Consequently benefits of wireless finance can be extended to customers with scant or poor credit histories with less risk to the institution than that incurred by credit card companies making it a suitable fit for financial inclusion.

\section{Problem Statement}

Even though the telecommunications and financial service industries share important traits, they have some fundamental differences that partnerships can help overcome. Telecoms need certain capabilities in order to provide wireless finance services. Those they do not already possess, they can acquire relatively cheaply by allying themselves with banks, and the combination can create competitive advantage with the right regulations (Wouter et al, 2010). Despite these mergers between financial players and telecommunication companies promising to address financial exclusion particularly those associated with access and business volume; positive effects especially of the transformational nature are yet to be realized because partnerships in Kenya have been rocky (M-kesho (CBK, 2012) M-shwari, KCB-M-pesa among others). Consequently take up of mobile banking products targeting poor and marginalized populations has been low as less than $1 \%$ of total digital transactions among low income households are digital (CGAP, 2015). Furthermore there is a tendency by actors to channel lots of effort on innovations that are additive as opposed to those that address financial inclusion So what ails the relationships in mobile banking and what needs to be done to stabilize these networks for sustained service delivery? Who are the actors in mobile banking? What are their roles in the emergent mobile banking networks? These are the questions that guided the research reported in this paper.

The specific objectives of the paper were to ascertain the usefulness of the Actor Network as a framework for informing trends in mobile banking and to determine the role of actors in the design, roll out and use of mobile banking products for financial inclusion.

\section{Literature Review}

The stabilization of various mobile banking products rolled out in Kenya has been precarious yet targeted segments have waited for services for a long time. In view of the complex relationships in the networks defining mobile banking, the paper seeks to introduce the following theories to inform discussions thereafter.

\subsection{The network society and its relevance to Mobile banking}

Mobile banking is dependent on the transmission of information through networks. These networks as envisioned in the network society (Castells 2004) are based on knowledge organized around networks and largely made up of flows. Flows are purposeful repetitive programmable sequences of exchange and interaction between physically disjointed positions held by the economic, political and symbolic structures of society (Franckle, Ham (2006). Communication between nodes in the disjointed positions creates a space of flows with business centers interconnected to other equivalent locales organized in a network that forms the actual unit of management, innovation and work.

Castells (2004), identifies three key components that support the space of flows:

- A circuit of electronic impulses that form the material basis for the processes that are strategically crucial in the network society.

- The nodes and hubs. The space of flows is not placeless although its structural logic is; as its electronic network links up specific places with well defined social cultural physical and functional characteristics. Hubs play a role of 
coordination for the interaction of all the elements integrated into the network. The functions to be fulfilled by each network define the characteristics of places that become their privileged nodes.

- The spatial organization of the dominant managerial elites that exercise the directional functions around which space is articulated. They manage the processes and flows in which the organizations are participating hence innovativeness and flexibility are important.

Since the networked practices are based on information flows processed between various sites by communication technologies, Castells points out that the space of the network society is made of the circulation of three elements:

- The places where activities and people enacting them are located

- The material communication networks linking these activities

- The content and geometry of the flows of information that perform the activities in terms of functioning and meaning

In the execution of activities of the network society, Castells places at the centre of the analysis the networking capacity of institutions, organizations and social actors as connectivity and access are essential. Essentially, the proper combination between information and communication technology, development of human capacity to take advantage of the full potential of these technologies and organizational restructuring based on networking becomes key to ensure productivity, competitiveness, innovation, creativity, power and power sharing (Franckle, Ham 2006).

Figure 1. Conceptualization of the execution process

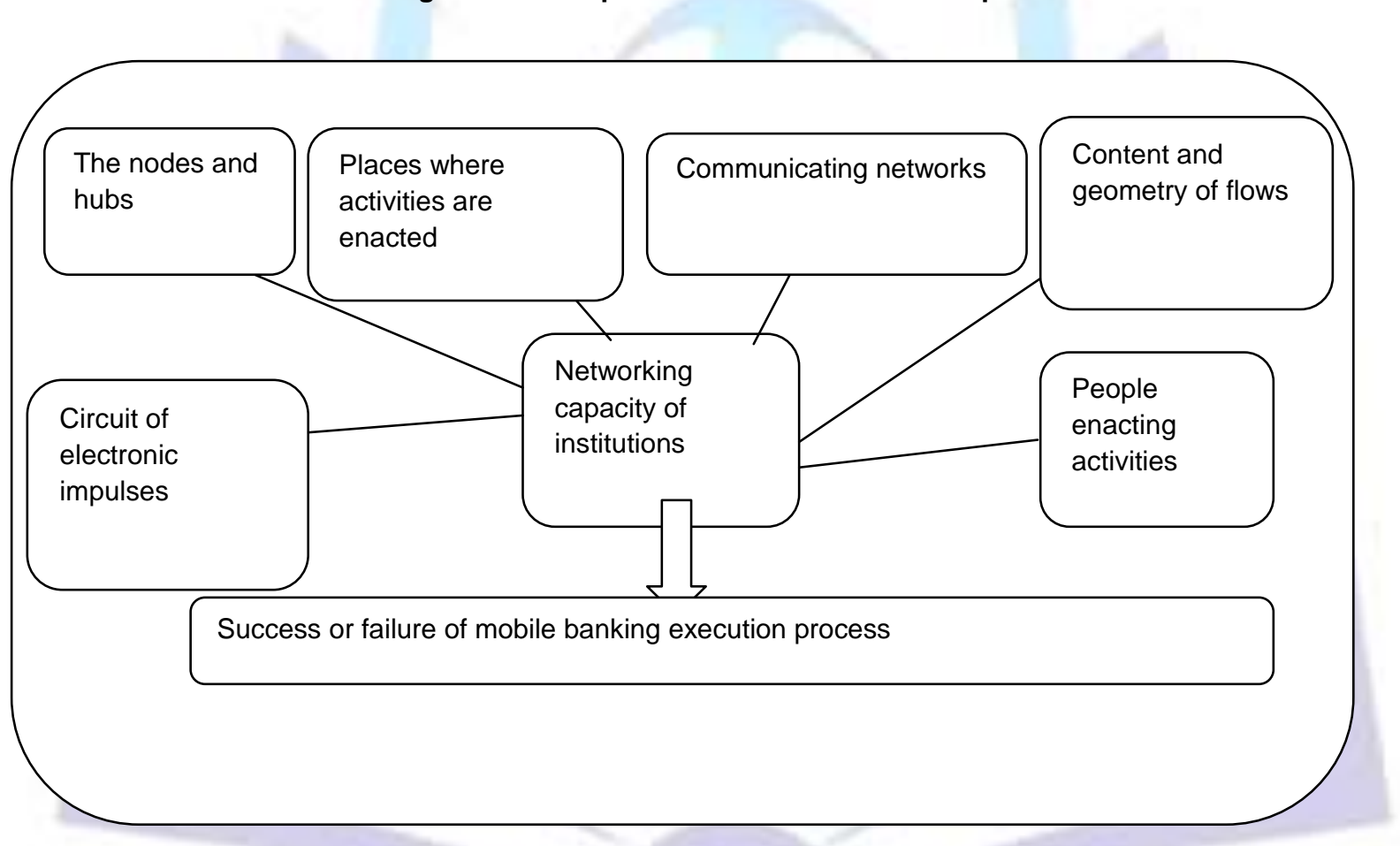

\section{Source: study}

The success or failure of a mobile banking execution process depends on the effectiveness of messages transmitted, the ability of the nodes to access services, the effectiveness of the hubs in provision of services, the attributes of the people using the services, the product design, the effectiveness of the networks and ultimately the strategies and techniques employed by the banks in the execution process.

\subsubsection{Network formation in Mobile banking}

The Actor Network Theory (ANT) addresses the actual rollout of mobile banking products creating a natural link of actors in the Network Society and the roles played by those actors in the rollout of mobile banking products. ANT is an umbrella theory that blends technology and society in a practical perspective and in effect the context in which mobile banking takes place and afforded this paper an opportunity of identifying and addressing issues of effective financial inclusion . ANT particularly stands out from the rest of the theories for the fact that neither the inherent properties of technology nor the properties of the social context drive the success or failure of the implementation of mobile banking rather the associations that exist and are created between the technology and its surrounding actor's (Hanseth 2004),) i.e. actors that are both technical and social. ANT proposes a new translation which focuses on associations rather than properties which is a radical deviation from ideas proposed in theories like Structuration by Giddens (1984). 
The ANT methodology is appropriate in the analysis of the set of negotiations that describe the progressive constitution of a network in which humans and non human actors assume identities according to prevailing strategies of interaction. In order to address the objective of financial inclusion by the mobile banking product, it is important to understand what elements are involved and how these elements map out their coexistence. In ANT the actor identities and qualities are defined during negotiations between the representatives of human and non human actants (Latour 1992) which entail:

1. Construction of common definitions and meanings - the product execution must be of relevance to the actors approached

2. Definition of representativities- the specific role of each actor approached must be spelled out. This spells out the functions of the actors in the execution of the product.

3. co-opt each other in the pursuit of individual and collective objectives- there is an agreement of the benefits to each actor at an individual level and at a collective level and consensus has to be reached on what each actor gets in order to enter into a partnership.

The ANT is a systematic way of bringing out the infrastructure that is used in the deployment of technological products. Neither the actor's size nor its psychological makeup nor the motivations behind its actions are predetermined. In other words actors in a network function as per definitions of that particular network, and the functions only measure up to the definitions of the network. Emphasis here is of that relationships are constructed at the time of the network formation. In the dynamics of networks, there are three analytical stages a network may undergo during a lifetime:

\section{i). Emergence.}

The attempt of an existing actor to grow and include new domains is the starting point in the emergence of a network. Through negotiations, intrigues, calculations, acts of persuasion and violence an actor engage in the process of translation ((Callon 1986; Callon 1981; Latour 1993)). Translation is the creation of actors and the process consists of four major stages

a) Problematization-. It is the stage and process where the focal actor sets to recruit others to partner in offering the product.

b) Interessment- this is the process of convincing other actors to accept definition of the focal actor. It involves the recruitment of actors.

c) Enrollment- this is the moment that actors accept the interests defined by the focal actor.

d) Mobilization - At this stage the actors are already enrolled and the solution gets wider acceptance. Compliance is ensured by monitoring the network and addressing descent as and when it arises. Networks emerge and are shaped by aligning more and more actors (Latour, 1992). Actors are isomorphic; their size and shape is not priori but the result of long development.

\section{ii) Development}

A network can develop into different directions, towards convergence or towards divergence. In networks where actors have successfully converged; the network as a whole stands behind any one of the actors who make it up. The more stable a network is, the better it defines its components, the smaller is the leeway for other networks to untie the connections in order to redefine the actor for his/her/its own purposes. The setting becomes a black box. The black box is not permanent and needs to be reinforced through intermediaries, however if the translation process is denied and actors leave, circulation of intermediaries becomes difficult and alignment becomes weaker and weaker, actors begin to diverge and the setting disintegrates.

\section{iii) Stabilization}

An actor network thrives for stabilization because none of the entities which make it up would exist without that network in that form. The stabilization of a network depends on the impossibility it creates of returning to a situation in which its current form was only one of possible option among others. The interpretive flexibility diminishes.

\section{Methodology}

The study was based on three mobile banking products availed in Kenya whose aim was to avail traditional banking services to un banked and under banked populations. The case study method was used as it allows an in-depth understanding of phenomena under study and adopts both the qualitative and quantitative research designs and hence blended well with the ANT methodology which aims at dissecting all elements animate and inanimate.

The population of the sampled County constituted the second largest number of poor people in the country at 619,148 over $70 \%$ of the total population was poor (Kenya Bureau of Statistics, 2012) and over 40 markets lacked bank branches. The populations were underserved and therefore considered appropriate for the study. Data sources were purposive dictated by the ontology of following actual users. An agents list was obtained from participating banks while users were identified at the outlets. Besides the quantitative data collected to measure user experiences, responses were further triangulated with Focus Group Discussions with agents and users. In-depth interviews were conducted with key informants to understand the motive behind mobile banking, design of the product to address needs of target markets, roll out strategies, challenges in the implementation process as well as mitigating strategies for emerging use experiences. 
Data from the interviews and the questionnaire was analyzed qualitatively and using the computer data analysis program SPSS respectively. An interpretation of the findings was done in respect to questions of the research tools with specific emphasis on those directly addressing the stabilization of mobile banking products for financial inclusion.

\section{Findings and interpretation}

Below are selected questionnaire items and responses by both users and agents.

The study established that each bank enlisted its own agents and was responsible for a differentiating structure to ensure that the model was a success hence the focal actor in each case. It was established that services offered at the agency across the different bank affiliations were basically cash in (deposits) and cashout (withdrawals) with additional value like balance enquiry, mini statements and account opening. No back office services were offered.

Figure 1: approximate commission per month in Kenya shillings

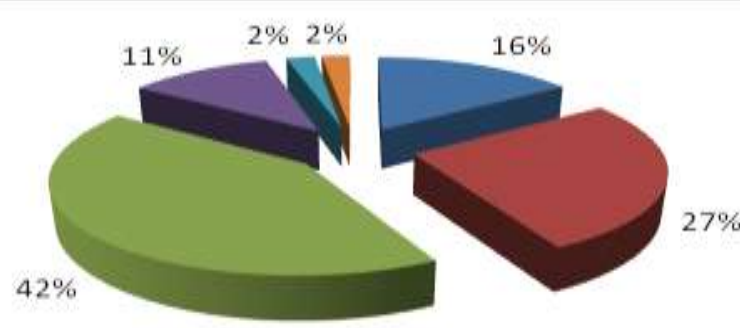

$$
\begin{aligned}
& =\text { less than } 1000 \\
& =1001-3000 \\
& =3001-5000 \\
& =5001-7000 \\
& =7001-10000 \\
& =>10000
\end{aligned}
$$

In regard to profitability, agents made little commisssion per month as shown in figure 2. $42 \%$ got between 3000 and 5000 as commission per month. $2 \%$ got less than 1000 while $27 \%$ got between 1000 and $3000.11 \%$ got between 5000 and 7000 . Only $2 \%$ got more than 10000 per month. A point to note is that close to $2 / 3$ of the agents made less than 5000 per month. Money which could not pay the assistant and take care of other bills.

The study revealed that agents had business strategies of attracting customers to their shops. This included opening early and closing late at $37.8 \%$, followed by investing enough capital at $22.2 \%$, training of assistants at $11.1 \%$ and assisting customers to transact at $8.9 \%$ as shown in figure 3. Other techniques mentioned included speaking the local language to customers and sometimes re-opening the shop after closing to transact for customers. The relationship between the shop assistants and their clients points to an informal relationship which has heavy undertones of cultural and communal influence as residents were able to determine how they wanted to be served.

Although agents were offering services to clients, they encountered various challenges Some of the challenges cited were that they did not have enough cash or float to serve customers effectively at $40 \%$, employees were tempted to steal cash they operated with and occasional burglary at $15.6 \%$, the network was not always effective making customers fail to trust the system at $11.1 \%$, the assistants offering the services lacked professionalism at $6.7 \%$ and that there were also few clients transacting in the shops per day at $13.3 \%$. These challenges were administrative and commitment in implementation process through negotiations for a better structure of the service would create an improved use experience.

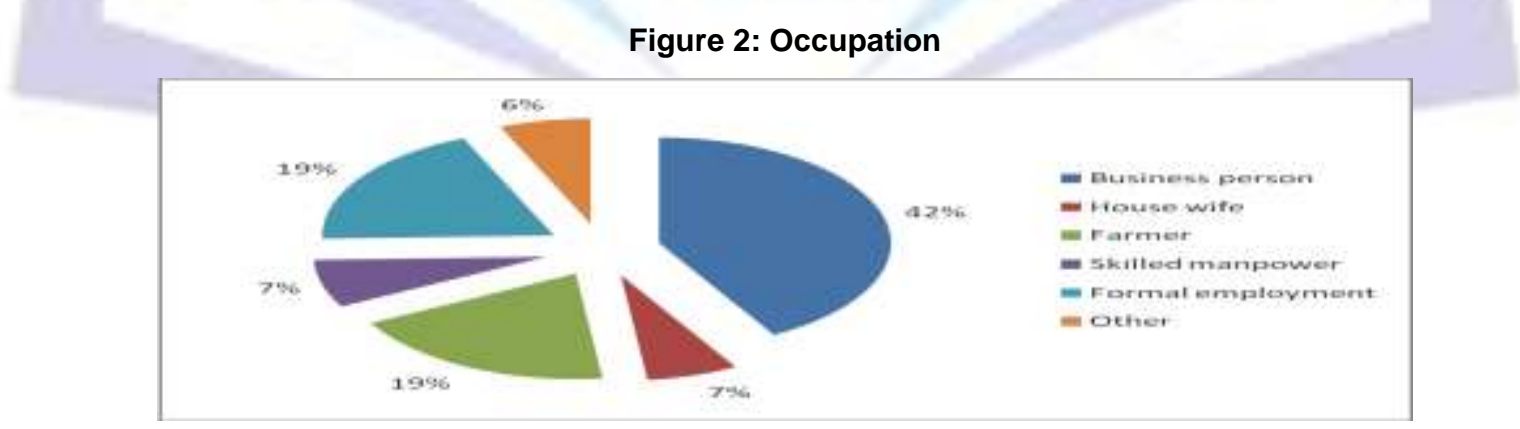

Majority of the respondents were business people at $42 \%$, with farmers and those in formal employment sharing at $19 \%$. Others included housewives as well as those offering skilled services at $7 \%$. This constitutes a significant finding and implication for this study. Only $19 \%$ of the population was a representation of the common rural folk (farmers?). This means that although financial services had been availed to rural poor populations it is not a guarantee that they will take up the services. There is need to establish what conditions are necessary for this segment to embrace financial services as well as technology based applications.

Mobile banking provided first opportunity for some people to be banked. reasons cited for being un banked included that there was no bank account in the area at $48 \%$, others were not aware of what accounts could do for them at $22 \%$ Some would have liked to own accounts but some banks required bank balances that were too high, $16 \%$ others could not afford fare to the nearest bank at $6 \%$ while $8 \%$ felt that requirements to open accounts were high. If the model availed to rural 
populations was to experience uptake and use, the barriers of cost and value for use would need to be addressed exhaustively. That was not the case and it contributed to the few transactions performed in a day.

Figure 3: Use of other financial services

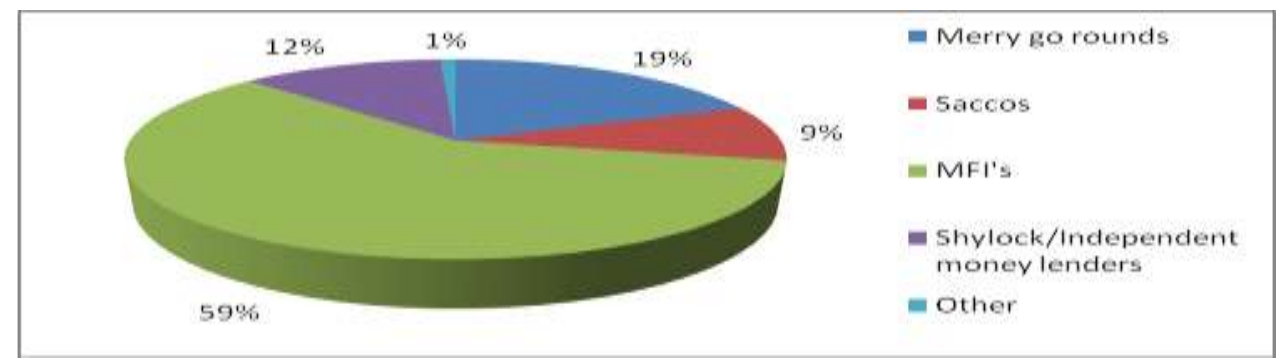

The study was keen to establish what alternative finacial services were available and evidence of use from respondents. $59 \%$ were positive that they had used MFIs, $19 \%$ had used Merry go rounds and $12 \%$ had borrowed money from money lenders (see figure 8 ). Only $9 \%$ had access to saccos. The findings point to the gap that prevailed and could be solved through formal services if agency banking services were stabilized for continued use.

\section{FGD - Users and agents}

The purpose for this focus group discussion was to enrich data collected through the guided questionnaire. The major findings included:

\section{i. Major needs}

Users were happy with agency shops particularly because they had bridged the mainstream financial access divide. They were in a position to access banking services conveniently in their locality and did not have to go to the main bank to attend to their banking needs. They appreciated the product structure of small amounts as their incomes were limited. The convenience of transacting in the normal commodity shops and the assistants intermediation made them feel comfortable. Convenience of time was also appreciated and in fact some said that even if the shops were closed they could request the owners to open and perform just that one transaction and once money was in their accounts they could initiate transactions on their own at home or anywhere at any time. They were able to decide how to use money in their accounts for various needs dividing the amounts to address needs as they deemed fit, they also chose whom to send money to without asking for assistance from anyone and in privacy.

Agents were optimistic that the products would pick with time and the businesses would be profitable. They attributed this hope to the business brands as the three cases were considered banks that targeted low end customers. Consequently each bank targeted a particular segment of customers, for example equity was popular with small value bankers as well as SMEs as they had a structure that allowed for flexible borrowing, Cooperative was popular with farmers and those who were in Micro Finance Institutions and Merry go rounds while KCB was popular with institutions and came in handy for schools and eased the payment of fees for users.

Users were now able to service payments for MFIs they had borrowed money from and the contributions to these groups were safely banked after the weekly meetings. Further they did not need to be in groups to access loans from the banks as individuals could get a loan on account of individual collateral or their new account history.

They also appreciated the fact that in banks repayment times were flexible unlike in the MFI or money lenders conditions where repayment of loans was on a specific date failure to which all group members were kept in the meeting by the officers in charge until the group contributed all the money due. Money borrowed from money lenders was expensive, before getting the borrowed money a certain percentage mostly $10 \%$ was paid in advance; further the repayment structure was harsh for most of the times it was on a weekly basis.

The mode of transacting was also very convenient as they were able to use their phone to initiate transactions and also confirm the same. Most of the banks gave cards in a week's time after opening an account and they could also use the cards to transact. Transaction charges were convenient as they only required airtime of less than Ksh 5 on average across all networks for an SMS. At the time of the study Yu charges were free. This was reasonable according to them as they saved transport costs to the branch and time wasted. Use of phones was convenient as those without phones could borrow phones and transact using their personal SIM cards where the virtual account resided; it was therefore not a requirement to own a phone but a mobile SIM card. Phones were easily charged at the market centre for as little as Ksh 10 , and depending on the make of the phone the charge could take up to three days. The users used the phone for all other communication needs.

\section{ii. Use experiences}

Although agent banking was a success story and had changed the lives of users, various challenges were cited. Key among the issues raised by agents was the number of clients trickling into the shops, as indicated in the field experience, we had to get telephone numbers of frequent customers from the agents in order to get some of them to answer questions as we could not get them at the shops transacting. Agents interviewed claimed it was because customers were not quite aware of the role of the product as customer awareness campaigns had not been frequent. First time account holders did 
not know how they would benefit from owning bank accounts nor did they possess any knowledge on the best banking practices; these people therefore needed financial literacy training.

Agents had challenges of capital, it was possible to get one customer collecting all the money held in cash or another depositing an equal amount to the e-money held in the float account, this led to disappointment of customers for changing cash to float or float to cash had to be done at the branch which was not near. The solution was to operate with a reasonable amount; a figure which stood at not less than Ksh 100,000. Most of them could not raise such amounts and were of the opinion that the banks they acted on behalf needed to revise lending rules to favor them as they were partners. Agents felt that interest rates at the time of the study were too high for businesses that were starting and commissions were minimal.

Theft was also an issue, most thieves associated agency banking with liquid cash, most of the times even when there was no cash in the shops thieves broke in leading to losses of other goods sold as upon missing cash they stole anything else that was in the shop. Workers employed were also tempted by the huge amounts of money they operated with and most of the times cash and float did not balance with the capital invested meaning that the workers lend themselves money. The fact that shops were in the neighborhood of the workers, relatives felt if they had a need they would easily borrow money to refund not knowing that the money was what was on sell in the agent shops. This led to unnecessary conflict and strained relationships.

Users also felt that agent shops needed to be increased so that they could complement each other. Most of the times if the only agent in the locality was in un able to offer a service, the users ware left with no option but to keep the money in the house which more often than not took care of other needs.

Participants were also concerned that besides the transaction costs all transactions attracted access charges for the SMS which was expensive. Members were also concerned that the transaction in the agency was more expensive than at the ATM, and were asking how an expensive product like that was going to add value to their lives, they claimed that they were being fleeced of their hard earned money.

Poor network services were a frustration that could hinder increased uptake and use. Both agents and users were not able to transact effectively as messages were occasionally not forthcoming. Such transactions were cancelled meaning that the service was not availed at the time of need taking the users back to the time the agency was non existent. The network coverage was also poor. Further from the market only designated areas had the network and people would be seen crowded in these areas trying to catch the signal.

\section{Interview with bank representatives}

User experiences were triangulated with the interview with banks officials to ascertain the way forward.

\section{i. Registration process}

The registration process according to the three was also frustrating as many entrepreneurs were interested in offering the services but could not be enlisted as they did not have the requirements as listed by Central Bank. They all wished that a review of the current regulation on agency recruitment would be done to allow for friendly agency models like the sub agent network.

\section{ii. Float issue}

Inability to serve customers effectively because agents did not have enough cash or e-money was a critical issue. One of the banks confirmed that there was a specific consideration given to agents when they sought financing for the business, but general consensus was that the interest rates were too high at the time of the study and repayment conditions applied. Due to the little commissions earned, the agent either qualified for small loans that could not transform operations or had to repay a bigger loan from other business sources.

\section{iii. Professionalism}

Bank representatives felt frustrated as some of the assistants did not go an extra mile to ensure that customers were served and served efficiently. These bank officials were in charge of agency banking and felt that they were not receiving utmost cooperation from shop assistants some who did not take agency banking seriously. Unfortunately these shop attendants were not directly employed by the bank and what the bank representatives could do was to communicate these frustrations to the owners of the businesses who would decide on whether to take action or not. Meanwhile these bank officials had targets to meet.

\section{iv. Tariff structure}

The SMS cost of transactions was thorny for all banks and the officials all agreed that it needed to be addressed. The study learned that discussions to this effect were being done at a 'higher level'. The officials were in agreement that a negotiated USSD model would be appropriate.

\section{ANT in relation to findings}

It was evident that mobile banking enlisted the roles of various actors in the construction of common definitions and meanings, defining representativities and co-opting each other in the pursuit of individual and collective objectives. Each actor identified was important in the successful execution of mobile banking services. The main goal of agent banking was to increase customer base and market share, provide a low cost solution to areas with potentially but with less number 
and volume of transactions, increase revenue from additional investment, interest and fee income and improve indirect branch productivity by reducing congestion in branches.

Identified actor's included:

\section{a.The focal actor}

Though the challenges cited by agents and users have persisted, banks seen as the focal actors for their specific agent banking product are now seriously translating the product to suit needs of the users as discussed here below.

\section{- Problematization}

In the endeavor to actualize the execution of mobile banking products to reach the unbanked populations, the three banks being the OPP in each products lifeline, set out to identify who the necessary partners were in the rollout of the product. As indicated in the case study the focal actors more or less followed the same translation process and the products were similar, the only difference was the actual models rolled out. The three cases identified the same actors as partners in the implementation of the products. One of the respondents had this to say,

'Our main partners are numerous, the product is complex and we have many partners on board. However our most valuable partners are our agents and users. Agents are the face of the bank out there and we are keen that they get their role right; users make it happen because they are our end users. The regulator is also significant as they give us guidelines on how to execute the product'.

What is missing in this statement is the realization that, the regulator may have an overall structure for agency operations but the guidelines need to be further negotiated to suit needs of targeted markets and hence escalate take up. The disconnect again is in the lack of understanding that the partnerships are not ordinary, but primed to suit each other's needs. The structure and execution must ensure that the product addresses the interests of all actors and which has not been demonstrated as ascertained from minimal transactions recorded. There are two implications for the focal actor. First is that they either do not have the resources or are unwilling (lack of commitment) to invest in the product or they lack the knowledge of the conditions of success of the product. Every aspect capable of causing failure in the network formation constitutes an actor in ANT; animate and inanimate, and further supported in Castells (2004) when he says that weaving of functions of all actors is depended on the networking capacity of institutions.

\section{- Interessment}

The focal actor further defined how relevant partners would benefit from the relationship. This was done through explanation of the proposal to identified partners with the aim of enlisting their contributions. This translation required skillful negotiations, powerful propositions, intrigues and calculations (like the exclusivity clause and exclusion from bank regulation as seen in the Safaricom case, Tarazi 2010) acts of persuasion and violence. The first and most crucial actor was the regulator, to whom successful interessment was done and eventual enrollment realized through the agent banking regulation. Some of the techniques emerging from the agent bank study include exchange of commissions as indicated in the survey results, the common goal of financial inclusion which was clearly stated, protection of customers, and business opportunity among others. If these partners are satisfied with the collective objectives, they accept to be enrolled and actively engage in the agency bank product execution program.

Literature reviewed suggests that aligning actors to the interests of the product is not uniform. Some actors may be rigid and this has been attributed to prescriptions in the current form which may need priming. It therefore calls for exchange of more intermediaries to ensure the roles are aligned. The regulator is one actor coming to mobile banking with heavy prescriptions, it is the responsibility of the focal actor to negotiate for the favorable regulation to facilitate scaling of the product.

\section{- Enrollment}

Enrollment of actors is crucial as execution of roles as defined will lead to stabilization while dishonesty, dissatisfaction or indifference in the execution will lead to disintegration. There are various actors enrolled in the mobile banking execution process, some of the crucial actors include:

\section{b.The regulator}

The main function of the regulators was to regulate the provision of agent bank services. Besides passing regulation to allow banks to offer banking services through third parties, the current regulation impacts negatively on the banks effort to reach scale. Some of the unfavorable conditions include the stringent due diligence requirements for agent's recruitment, unclear guidelines on how to regulate mobile-bank related tariffs, impractical and superficial regulation on customer protection in case of loss of money as a result of use of these services and the passing of liability exclusively to agents.

\section{c.Agents}

Agents are required to offer agent banking services to customers as regulated in the Agent banking act. These services include taking deposits, withdrawals, facilitating bill payments, mini statements, bank balances and balance inquiry. Besides this they should offer the services professionally and exercise utmost people's skills as they offer the services. The study established that KCB has an extensive training program for its assistants, taking them through customer care skills and public relation skills before being able to offer the services. The agents have been able to conveniently offer the services in residential areas and markets near to customers, which is a considerable gain for agent banking. They also 
offer the services at flexible times most of them opening early and closing late. Other attributes include that they assist customers who are unable to transact on their own as well as going the extra mile to explain issues to customers in local languages. However for increased uptake and use suggestions from users include that they should invest enough in order to perform transactions needed whether cash or electronic, that the assistants need to be more professional and of reasonable credibility.

\section{d.Users}

Users are the targets of these products. The study revealed that they appreciated services offered at the agent outlets. There was evidence of changed lives as users were able to save money conveniently after work, deposit money and withdraw the same, pay school fees for their children conveniently, use statements for other services, receive payments via the new accounts, access services conveniently near their homes and at flexible hours and transact at convenience in their own homes in line with gratifications associated with the network society (Jentri Anders (2006). However various challenges hindered their increased uptake and use. These included that confirmation messages for transactions were not always forth coming due to ineffective networks, most of the times they were not served as agents did not have enough cash or e-money. They also did not trust some of the assistants employed in agencies as they were of questionable integrity.

\section{d.MNOs}

The study has not established any significant translation in the role played by MNOs. The tariff applied for access is not any different from that applied to normal SMS communication. The efficiency of the network is poor as confirmation messages for initiated transactions sometimes are not forthcoming. A suggestion for a solution for this problem was an allocation of a bandwidth specifically for agency banking. While this is a viable and possible remedy, it has not been done. Again the poor relationship between MNOs and banks in the whole ecosystem is registered. Some banks are now pursuing their own network licenses (Finextra 2014)

\section{- Mobilization}

It was evident from the experience survey and discussions that agent banking had changed the lives of users studied. They were now able to access banking services conveniently. However challenges faced could impact negatively on the uptake and use and mobilization strategies needed to focus on emerging issues. It was necessary for an effective network to be sought in order to create confidence in services offered, the effectiveness of services to be enhanced by the banks supporting agents financially and in branding of shops for effective advertising. Education on the importance of banking and best practices was important for these would encourage new accounts and that training of assistants was crucial to encourage quality through professional service. Increased use would in effect improve agent earnings and the agents would be able to remunerate their workers reasonably and limit theft by servant and also enable them acquire permanent premises with better security.

Drawing from the actual study findings and the secondary data, mobilization specific to mobile banking for increased uptake and use include that:

The volume of transactions and the number of agents to offer these services have to go hand in hand i.e. a large number of agents to create access and a large number of users to support the services (Castells, 2004). As indicated earlier services offered attract little income and it's not through the amount transacted but with what frequency, the more transactions done the better the business. Value is obtained per transaction, in that every transaction counts significantly. It is for this reason that mass products of the agent banking nature need to be scaled first both in provision and in actual use for the volume to create a critical mass.

As demonstrated in the findings of the survey with agent's majority lacked capacity to serve customers and a financing strategy for the agents by the main actors would ensure that clients build trust in the products and hence improved translation.

Awareness campaigns are crucial for any new product. And products that require demonstrations of usage require platforms for demonstrations and one on one explanation. Specific to agent banking is the need for customer education, at the time of the study only Equity bank had embraced this strategy through the FIKA initiative (Financial Knowledge for Africa was a partnership with the MasterCard Foundation to provide entrepreneurs with business management skills however the good thing is that they were doing it for customers across board.

\section{Conclusion}

Mobile banking is a new phenomenon and with it comes a paradigm shift in the role played by users; where institutionalization of services paves way for individual autonomy exhibiting descriptions of the network society. Target clients will no longer be held hostage by institutionalized procedures as well as scheduled service delivery, in the inverse they will be in a position to decide on how and when to engage with services they require. The implication is that the success of the service will highly depend on the ability of users to engage with the services in ways beneficial to them. Meaning that there is need for them to be empowered with knowhow, mobile phones, availability of services as well as affordability.

Consequently from the foregoing discussion it is evident that the implementation of mobile banking products is dynamic and complex. The characteristics that make mobile banking promising; its scale and impact, its multiple uses as well as its 
novelty also contribute to the challenges faced in realizing them. Tenets of the Actor network theory are critical in addressing network formation challenges as well as sustenance for the realization of financial inclusion.

\begin{abstract}
Mobile banking deployments target customers who may be poor, dispersed, and remote and spans two distinct industries with different business models i.e. the banking and the telecommunication industries. Developing the necessary crosssectoral partnerships including bridging cultures and regulations may therefore be difficult (Martina 2012). In addition the relationships are under threat of disintegration and the relationship building is continuous. With these challenges, translation can be ineffectively done in such a way that the roles played do not lead to the growth of the network. Without deliberate efforts informed by ANT, sustenance of the partnerships which constitute the products targeting financial conclusion would continue recording insignificant results. Weaving actions of each together for a common goal call for a succinct understanding of the processes involved and consequences of failure to play roles assigned effectively. Understanding the intentions of each actor in an intense translation process will ensure that mistakes are not made. All the actors are important and the network cannot exist without the contribution of all enrolled actors. It is important for focal actors to realize that the execution process does not constitute a boardroom decision but a series of negotiations with various partners without whom the product is doomed. In addition the success of mobile banking products is dependent on scale and these products represent a two sided market, whereby new deployments must convince both agents (supply) and customers (demand) to sign up for the service in sufficient quantity to be viable.
\end{abstract}

Not all actors in a network embody the same level of flexibility (Law (1999) and Callon (1993:183). Actors embody various characteristics that are the outcome of their relationships and heterogeneous elements animate or inanimate that have been linked to one another. The characteristics are renegotiated in the interplay with other actors leading to priming. These forces are existing rules governing the existence of these elements. Each actor has been considered to participate by virtue of the relevant role (prescriptions) each has for the network. Each of these actors participates by the virtue of what they can do for the network. However depending on the realignment required allowing the roles of each actor to fit and function according to requirements of the new network, some elements may resist change. An example is the standard SMS charge for a single SMS. Reducing tariffs from the standard charge may require more effort in the negotiation and exchange of more intermediaries. These realizations are necessary during the translation process; probably the thorny relationship between Safaricom and Equity would be resolved if an understanding would be struck in regard to who contributes what to the success of the network and commensurate intermediaries accorded.

The foregoing discussions are therefore critical in this defining moment where the model is right for financial inclusion but implementation is precarious. ANT is clear that every single actor (animate or inanimate) needs to be followed to ascertain that their roles are played and consequently benefits for the partnership realized. All focal actors must realize that mobilization is key to the sustainability of mobile banking products rolled out if financial inclusion is to be attained.

\title{
REFERENCES
}

1. Allafrica Global Media (2015). Kenya: Safaricoms Lipa Na M-pesa takes lead in cashless transactions. Available at allafrica.com/stories/201412050163/html

2. Callon, M. (1986). The Sociology of an Actor Net-Network: The Case of the ElectricVehicle.pp. 19-34 in Callon, Michel; Law, John; Rip, Arie (eds.) Mapping the Dynamics of Science and Technology. London: MacMillan

3. Callon, M. (1992). The Dynamics of Techno-Economic Networks. pp. 72-102 in Coombs, Rod; Saviotti, Paolo; Walsh, Vivien (eds.) Technological Change And Company Strategy: Economic and Social Perspectives. London, San Diego: Harcourt Brace Jovanovitch

4. Callon, M., Latour, B. (1981). Unscrewing the Big Leviathan: How Actors Macro-Structure Reality and How Sociologist Help Them To Do So. pp. 277-303 in Knorr-Cetina, K.

5. Castells, M. (2004). "An Introduction to the Information Age" in The Information Society Reader, Frank Webster, Raimo Blom, Erkki Karvonen, Harri Melin, Kaarle Nordenstreng, and Ensio Puoskari, editors. London and New York: Routledge, 2004. pp 138-49.

6. Castells, M. (2004). The Network Society. A Cross-cultural Perspective: Edward Edgar publishing.

7. CBK (2010). Mobile Banking Act 2010. Available at. http://centralbank.go.ke/downloads/mobilebanking/act.pdf.

8. CCK. (2012). Statistics Sector Report 2011/2012 Available at www.cck.go.ke/rsc/statistics/SECTOR REPORT Q11011.pdf

9. CCK. (2014). Statistics Sector Report 2013/2014 Available at www.cck.go.ke/rsc/statistics/SECTOR REPORT Q11011.pdf

10. CGAP (2015). Digital financial services. Available at www.cgap.org/digital-finacial-services.

11. Finextra (2014). Equity Bank to take on M-pesa with Thin SIM Technology accessed on 26/01/2015. Available at https:www.fiextra.com/news/fullstory.aspx 12. Franckle, Ham $\quad$ (2006).
http://www.ru.nl/socgeo/html/files/geoapp/werkstukken/Castellsflows.pdf 
13. Fredrik, B., and Martin P. (2009). Assessing Factors Influencing the Diffusion of Mobile Banking in South Africa: a case study on the Company Wizzit. School of Business Economics and Law, Gothenburg University.

14. Giddens, A. (1984). The Constitution of society: outline of the Theory of Structuration. Cambridge: Polity.

15. Hanseth, O. Aanestad, M. (2004). Actor-network theory and infrastructure standards. Accounting , Management \& Information Technology 7(4):183-211.

16. ITU (2008). infoDev ICT Regulation toolkit. UA Module: http:// thornton.co.za/resources/gg31333-nn987-pg2-31.pdf.

17. Jentri A. (2006). Beyond counterculture: The Community of Mateel. Washington University Press

18. KNBS (2012). Kenya National Bureau of statistics available at www.knbs.or.ke

19. Latour, B. (1986). The powers of association. In Law J. (ed). Power and Belief. A New sociology of Knowledge. London: Rutledge.

20. Latour, B. (1992). The Sociology of a Few Mundane Artifacts. in Bijker, Wiebe; Law, John (eds.) Shaping Technology / Building Society Studies in Socio-technological Change. Cambridge, MA: MIT Press

21. Latour, B. (1993). We Have Never Been Modern (translated by C. Porter). New York, London.

22. Martina Mulwa (2012). The Role of Wireless Communication in Financial Inclusion. A Case Study of Selected Mobile Banking Products in Makueni County. A Dissertation Submitted at the School of Journalism and Mass Communication University of Nairobi. URL:erepository.uonbi.ac.ke/handle/11295/8457

23. Martina Mulwa and Ndeti Ndati (2013). Integrated Marketing Communication and Technology Adoption: A Case of Safaricom's M-PESA Mobile Money Transfer Services in Kenya. African Journal of Science, Technology, Innovation and Development, 2013 Vol. 5, No. 5, 363-371, http://dx.doi.org/10.1080/20421338.2013.829297

24. Porteous, M. (2007). The enabling environment for mobile banking in Africa. London: DFID

25. Tarazi, M., and Paul B. (2011). "Regulating Banking Agents." Focus Note 68. Washington, D.C.: CGAP, March.

26. World Bank (2012). Information and Communications for Development 2012: Maximizing the Mobile: Washington DC: World Bank

27. Wouter R., Adam S., and David,O. (2010). Why banks and Telecos must merge to Surge. Available at www. Strategybusiness,com/article/17163?gkp=4cda6

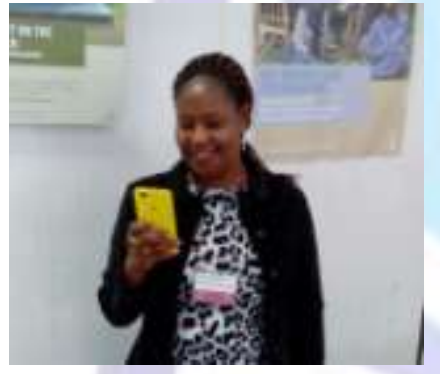

\section{Author's biography with Photo}

Dr. Martina Mutheu holds a PhD in Communication and Information studies from the University of Nairobi and is a lecturer at the School of Journalism and Mass Communication in the same Institution. She has published papers on mobile money in various journals and also presented papers in various conferences in Africa. She is an active mobile money practitioner in Kenya. She is the founder of M-ASCA (Mobile Accumulating Savings and Credit Association) an indiscriminate mobile phone based Accumulating Savings and Credit Association whose aim is to bring community members together in order to improve their livelihoods. It targets every adult Kenyan irrespective of their background who may not hold any collateral but are interested in saving in order to access affordable credit for investment, business start ups, old age savings or any other viable need. Using her innovation; the M-ASCA Model, a USSD based mobile phone platform and therefore anytime anywhere, members register, save, borrow, guarantee one another and repay loans through the phone.

\section{Prof. Timothy Mwololo Waema}

Timothy Mwololo Waema is a Professor of Information Systems in the School of Computing and Informatics in the University of Nairobi. He holds a Ph.D. degree in Strategic Management of Information Systems from the University of Cambridge (UK) and a Bachelors Honours Degree in Electrical and Electronics Engineering from the University of Bath (UK). His research interests are in information systems planning, design and implementation; ICT policy; and different aspects of ICT for development, including e-governance, ICT and poverty and agri-informatics. He is the Chairman of Management Board of the Kenya Education Network, the national research and education network. Prof. Waema has published widely in journals, conference proceedings and in books. He has edited two books, one on electronic governance and the another on ICTs and poverty. He sits on editorial boards of several peer reviewed journals, including being in the Editorial Board of the African Journal of Science, Technology, Innovation and Development (AJSTID) and being the Book Editor in the International Journal of Computing and ICT Research (IJCIR). He is a Professional Member of the Association for Computing Machinery (ACM), the largest association of computing professionals globally. 